\title{
Monogagaine, a Novel Dimeric Indole Alkaloid from Tabernaemontana chippii and Tabernaemontana dichotoma [1]
}

Teris A. van Beek ${ }^{* a}$, Peter P. Lankhorst ${ }^{\mathrm{b}}$, Robert Verpoorte ${ }^{\mathrm{a}}$, Georges Massiot ${ }^{\mathrm{c}}$, Roel Fokkens ${ }^{\mathrm{d}}$, Cornelis Erkelens ${ }^{\mathrm{b}}$, Premila Perera ${ }^{\mathrm{e}}$, and Cecilia Tibell ${ }^{\mathrm{e}}$

${ }^{a}$ Department of Pharmacognosy, Gorlaeus Laboratories, P.O.Box 9502, 2300 RA Leiden, The Netherlands

${ }^{\mathrm{b}}$ Department of Organic Chemistry, Leiden, The Netherlands

${ }^{\mathrm{c}}$ Faculté de Pharmacie, Reims, France

${ }^{\mathrm{d}}$ Laboratory of Organic Chemistry, Amsterdam, The Netherlands

${ }^{e}$ Department of Pharmacognosy, Uppsala, Sweden

Z. Naturforsch. 40b, 693-701 (1985); received December 5, 1984

Monogagaine, Novel Dimeric Indole Alkaloid, Tabernaemontana chippii, Tabernaemontana dichotoma, Antimicrobial Activity

From the rootbark of Tabernaemontana chippii and the stembark of $T$. dichotoma a novel dimeric indole alkaloid was isolated which was named monogagaine. It was assigned structure 1 on the basis of spectral data. It showed antimicrobial activity against Bacillus subtilis.

\section{Introduction}

Recently we have reported on the tertiary alkaloids occurring in Tabernaemontana chippii [2] and T. dichotoma [3] (Apocynaceae). From the rootbark of T. chippii, collected in Ivory Coast, 45 indole alkaloids belonging mainly to the corynanthean, ibogan and dimeric corynanthean-ibogan classes were isolated [2]. From the stembark of the Sri Lankian T. dichotoma, 22 alkaloids were isolated belonging primarily to the same classes [3].

One minor alkaloid was independently isolated from both species. In previous publications it was provisionally given the code names $6 \mathrm{~F}$ and $20 \mathrm{~A}$ for $T$. chippii and $T$. dichotoma respectively. Approximately $3 \mathrm{mg}$ of monogagaine was isolated from $T$. chippii and approximately $1 \mathrm{mg}$ from $T$. dichotoma. The spectral data (UV, EI-MS and ${ }^{1} \mathrm{H}$ NMR at $300 \mathrm{MHz}$ ) which were available for this alkaloid at the time of writing the previous publications did not allow its structure elucidation although it could be concluded then that it was not a known alkaloid. Since then more spectral data (FD-MS, high resolution EI-MS, CD, $500 \mathrm{MHz}{ }^{1} \mathrm{H}$ NMR, 2D COSY ${ }^{1} \mathrm{H}$ NMR at $500 \mathrm{MHz}$, NOE difference experiments and ${ }^{13} \mathrm{C}$ NMR) have become available and with the help of the new data it has been possible to propose a structure for the novel dimeric indole alkaloid. The

\footnotetext{
* Reprint requests to T. A. van Beek.

Verlag der Zeitschrift für Naturforschung, D-7400 Tübingen 0340-5087/85/0500-0693/\$01.00/0
}

new alkaloid was named monogagaine after the collection site of $T$. chippii in Ivory Coast. In the following we wish to report about the structure elucidation of monogagaine.

\section{Results and Discussion}

The alkaloid gave a gold colour with the ferric chloride perchloric acid spray reagent which changed via dark blue to grey-black upon heating. Such a colour behaviour is typical for dimeric $T$. alkaloids [4]. The UV spectrum showed maxima at 222 and $288 \mathrm{~nm}$ and shoulders at 282 and $297 \mathrm{~nm}$ and is thus purely indolic. The EI-MS showed the molecular ion at $m / z 600$ which was confirmed by a FD-MS. Further intense fragments were observed at $\mathrm{m} / \mathrm{z}$ 492, 491, $490,182,180(100 \%), 133$ and $\mathrm{m} / z$ 122. The three fragments at $\mathrm{m} / \mathrm{z} 182,180$ and $\mathrm{m} / \mathrm{z} 122$ are typical for a 3'-vobasinyl half (3). However, the $500 \mathrm{MHz}$ ${ }^{1} \mathrm{H}$ NMR spectrum (Fig. 1) did not confirm the presence of such a half. All the other dimeric indole alkaloids isolated from T. chippii and T.dichotoma do possess such a half which is readily recognized by certain characteristic signals such as the $\mathrm{N}$-methyl group around $2.6 \mathrm{ppm}$, the shielded carbomethoxy group around $2.45 \mathrm{ppm}$, the $\mathrm{H} 16$ around $2.75 \mathrm{ppm}$, $\mathrm{H} 21_{\mathrm{s}}$ around $2.9 \mathrm{ppm}$ and $\mathrm{H} 14$ around $1.9 \mathrm{ppm}$. In all the dimers containing a vobasinyl half isolated so far the observed coupling constants and the chemical shifts of these vobasinyl protons are very constant. However, none of these signals could be observed at their usual position. Therefore it was concluded that 

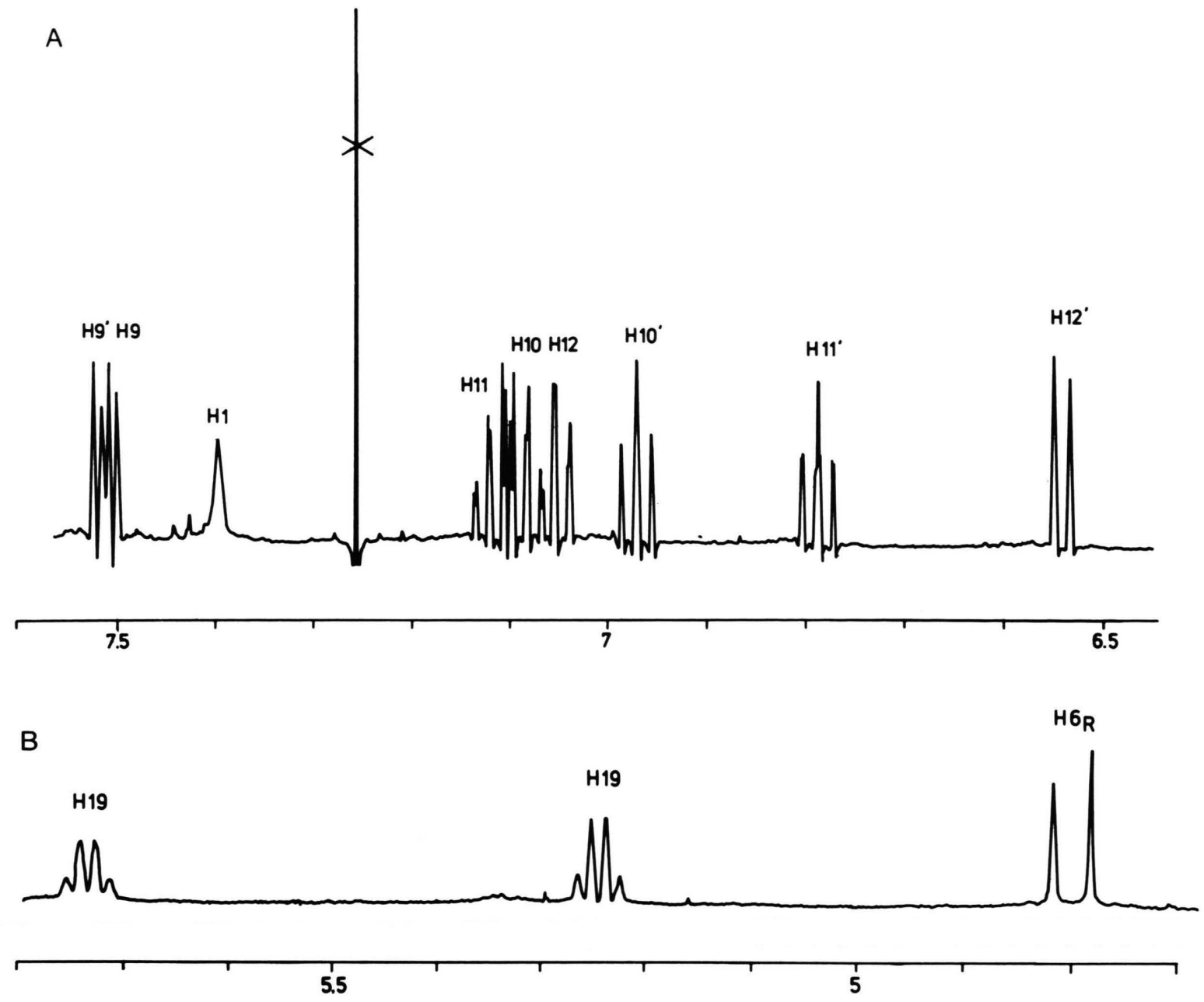

C
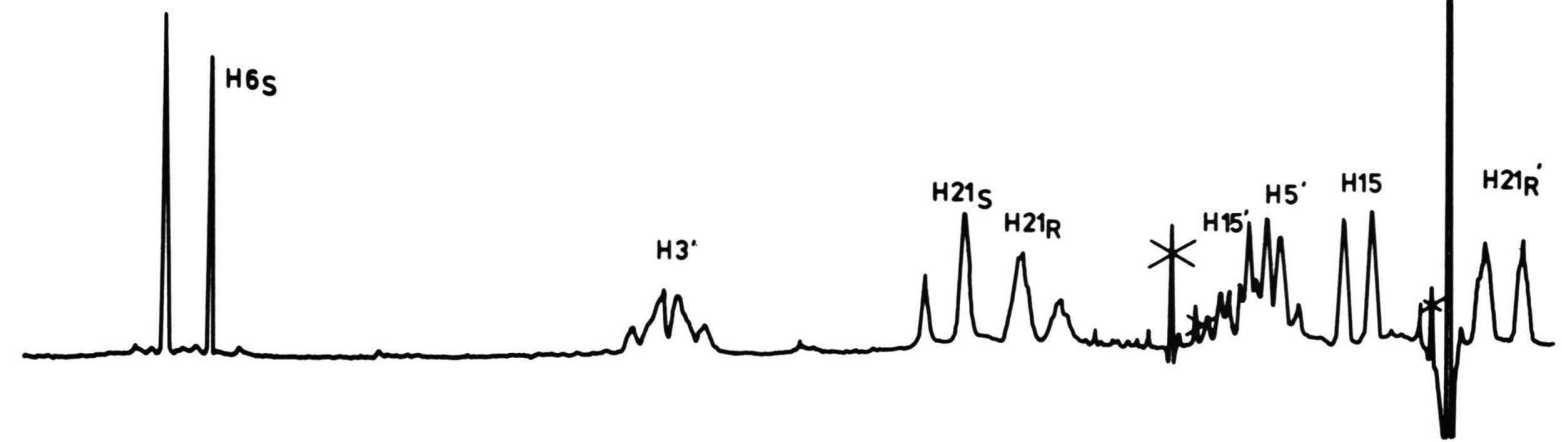

4.5 
D
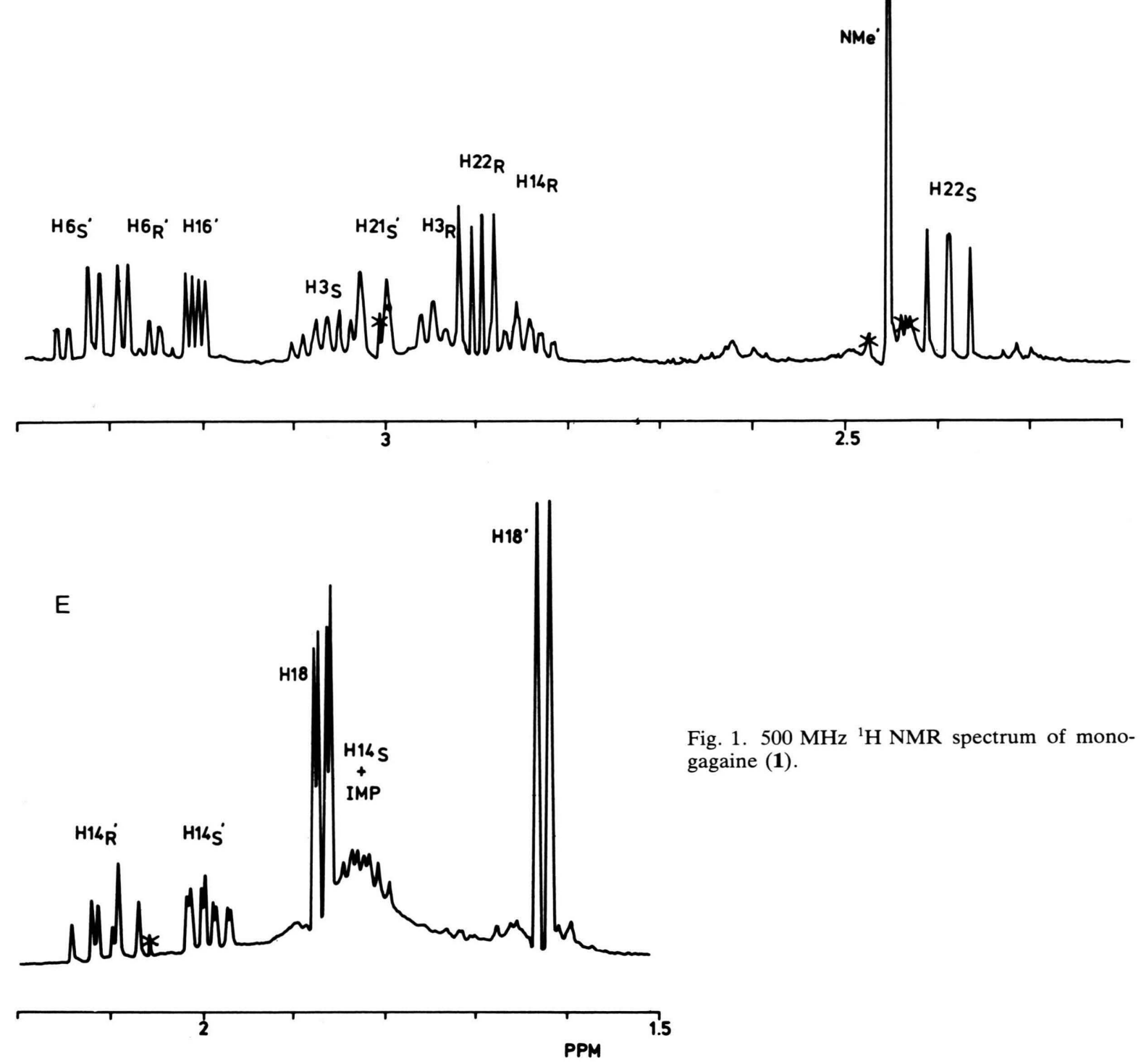

either a vobasinyl half was present but in a different conformation with a simultaneous change of the chemical shifts and coupling constants or that no vobasinyl half was present at all. The EI-MS data favoured the former possibility. Other striking features of the $500 \mathrm{MHz}{ }^{1} \mathrm{H}$ NMR, some of which were not readily observable at $300 \mathrm{MHz}$, were the pre- sence of two unsubstituted aromatic rings, only one indolic $\mathrm{NH}$, two ethylidene side chains, two $\mathrm{AB}$ doublets $(J=17.7 \mathrm{~Hz})$ at 4.80 and $4.45 \mathrm{ppm}$, a carbomethoxy group at $3.47 \mathrm{ppm}$ and an $\mathrm{N}$-methyl group at $2.45 \mathrm{ppm}$. The two unsubstituted aromatic rings indicated a different way of attachment between the two halves than is normal for dimeric $T$. alkaloids 
[5]. This and the $\mathrm{AB}$ doublets at 4.80 and $4.45 \mathrm{ppm}$ reminded us of the alkaloid vobparicine (5) which was also isolated from T. chippii [6]. Vobparicine, a dimer of the new apparicine-vobasinol type also showed its molecular ion at $\mathrm{m} / \mathrm{z} 600$ and a high resolution MS of monogagaine showed that the bruto molecular formula of both alkaloids was identical $\left(\mathrm{C}_{39} \mathrm{H}_{44} \mathrm{~N}_{2} \mathrm{O}_{2}\right)$. The rest of the aliphatic part of the ${ }^{1} \mathrm{H}$ NMR spectrum was complex although there was relatively little overlap at $500 \mathrm{MHz}$ (Fig. 1). The determination of all chemical shifts, coupling constants and proton-proton connectivities was possible by means of a 2-dimensional COSY ${ }^{1} \mathrm{H}$ NMR spectrum at $500 \mathrm{MHz}$ (Fig. 2). Apart from the methyl groups the proton signals of the following spin systems were found to be present in the region from 4.2 to $1.5 \mathrm{ppm}$ : one large $\mathrm{CH}_{2}-\mathrm{CH}-\mathrm{CH}-\mathrm{CH}-\mathrm{CH}_{2}-\mathrm{CH}-\mathrm{CH}_{2}$ spin system, one smaller $\mathrm{CH}_{2}-\mathrm{CH}_{2}-\mathrm{CH}$ spin system and two isolated $\mathrm{CH}_{2}$ systems. The large spin system strongly suggested a $3^{\prime}$-vobasinyl half albeit in a different conformation and with an extra methylene group attached to $\mathrm{C} 3$. Also it ruled out the presence of a rearranged ervatamine system. The chemical shifts and especially the coupling constants of the smaller spin system resembled strongly the $\mathrm{C} 3 / \mathrm{C} 14 /$ C15 spin system of O-acetyl-vallesamine (6) (Table I) while the two isolated $\mathrm{CH}_{2}$ spin systems are typical for two different pairs of geminal $\mathrm{H} 21$ protons.

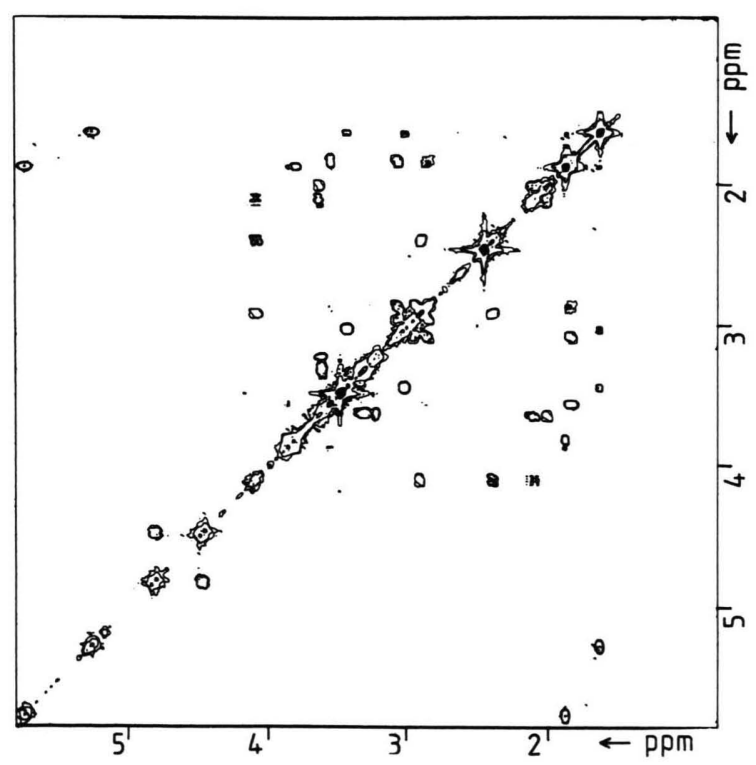

Fig. 2. COSY spectrum of monogagaine (1).
Based upon the following considerations: a) the chemical shifts and coupling constants of all protons, b) the absence of the C16-C22 double bond which is present in vobparicine (5) and thus, c) the necessity of two bonds between the two halves to account for the same number of protons as in vobparicine, d) the missing of one indolic $\mathrm{NH}$ and e) biosynthetical reasoning the basic structure 7 was proposed for monogagaine. No stereochemical relationships are indicated in 7 except for $\mathrm{H} 15$ and $\mathrm{H}_{15}$. These two protons were assumed to possess the same absolute configuration as in secologanin and all other nonrearranged monoterpenoid indole alkaloids. The only difference with vobparicine (5) is the absence of the C16-C22 double bond and the formation of a new bond between the vobasinyl nitrogen and the apparicine $\mathrm{C} 16$. In the ${ }^{13} \mathrm{C}$ NMR spectrum which was subsequently recorded, all the carbons appeared at values where they could be more or less expected (Table II). The assignment of certain signals could not be confirmed by an off-resonance spectrum because the amount isolated precluded the recording of such a spectrum. Interesting was the $3 \mathrm{ppm}$ downfield shift of the carbons of the carbomethoxy group if compared with the values of these carbons in a normal vobasinyl half. Together with the $1 \mathrm{ppm}$ downfield shift of the methyl protons of the carbomethoxy group in the ${ }^{1} \mathrm{H}$ NMR spectrum this indicated that the carbomethoxy group no longer lies above the indole nucleus. Additional evidence for the substitution at the indole nitrogen of the vobasinyl half was found in the unusual non-indole-like shifts of the aromatic protons of this half $(7.51,6.97$, 6.79 and $6.55 \mathrm{ppm})$. Similar shifts $(7.46,7.01,6.84$ and $6.55 \mathrm{ppm}$ ) were recently published for the dimeric indole alkaloid kopsoffine which possesses a similar $\mathrm{N}$-substituted indole [7].

The most likely MS fragmentation pattern which accounts for the formation of the intense fragments at $m / z 492,491$ and $m / z 490$ is presented in Fig. 3. An alternative mechanism is the initial breaking of the C6-N 4 bond followed by the breaking of the $\mathrm{C} 15-\mathrm{C} 16$ bond, also resulting in the loss of the unsubstituted ethylpiperidine moiety of the apparicine half.

By means of Dreiding models, the determined coupling constants (Table I) and the Karplus equation the relative stereochemistry of all carbon atoms with the exception of the spiro atom $\mathrm{C} 16$ and the conformation of most of the rings could be deter- 
Table I. ${ }^{1} \mathrm{H}$ NMR data monogagaine, $\mathrm{O}$-acetyl-vallesamine and $3^{\prime}$-vobasinyl half of vobparicine $\left(\mathrm{CDCl}_{3}, 500,300\right.$ and $500 \mathrm{MHz}$ respectively).

\begin{tabular}{|c|c|c|c|c|}
\hline & \multicolumn{2}{|c|}{ Monogagaine } & \multicolumn{2}{|c|}{ O-Acetyl-vallesamine } \\
\hline H-nr & $\delta$ & $J(\mathrm{~Hz})$ & & $J(\mathrm{~Hz})$ \\
\hline 1 & 7.40 & bs & 8.72 & bs \\
\hline $3_{R}$ & 2.94 & $14.3\left(3_{\mathrm{S}}\right), 7.0\left(14_{\mathrm{R}}\right), \sim 1\left(14_{\mathrm{S}}\right)$ & 2.88 & $13.7\left(3_{\mathrm{S}}\right), 6.8\left(14_{\mathrm{R}}\right), \sim 1\left(14_{\mathrm{S}}\right), \sim 1\left(21_{\mathrm{S}}\right)$ \\
\hline $3 \mathrm{~s}$ & 3.07 & $14.3\left(3_{R}\right), 12.4\left(14_{R}\right), 6.1\left(14_{S}\right)$ & 3.00 & $13.7\left(3_{R}\right), 12.7\left(14_{R}\right), 5.3\left(14_{S}\right)$ \\
\hline $6_{\mathrm{R}}$ & 4.80 & $17.7\left(6_{s}\right)$ & 4.83 & $17.6\left(6_{s}\right)$ \\
\hline $6_{s}$ & 4.45 & $17.7\left(6_{R}\right)$ & 4.18 & $17.6\left(6_{R}\right)$ \\
\hline 9 & 7.50 & $7.7(10), 1.3(11)$ & 7.48 & $8.0(10), 1.2(11),<1(12)$ \\
\hline 10 & 7.08 & $7.7(9), 7.7(11), 1.3(12)$ & 7.10 & $8.0(9), 7.0(11), 1.2(12)$ \\
\hline 11 & 7.12 & $1.3(9), 7.7(10), 7.7(12)$ & 7.22 & $1.2(9), 7.0(10), 8.0(12)$ \\
\hline 12 & 7.05 & $1.3(10), 7.7(11)$ & 7.32 & $<1(9), 1.2(10), 8.0(11)$ \\
\hline $14_{R}$ & 2.85 & $7.0\left(3_{\mathrm{R}}\right), 12.4\left(3_{\mathrm{S}}\right), 13.8\left(14_{\mathrm{S}}\right), 1.8(15)$ & 2.33 & $6.8\left(3_{R}\right), 12.7\left(3_{S}\right), 14.7\left(14_{S}\right), 2.6(15)$ \\
\hline $14_{s}$ & 1.83 & $\sim 1\left(3_{R}\right), 6.1\left(3_{S}\right), 13.8\left(14_{R}\right), 10.9(15)$ & 2.03 & $\sim 1\left(3_{R}\right), 5.3\left(3_{S}\right), 14.7\left(14_{R}\right), 11.4(15)$ \\
\hline 15 & 3.54 & $1.8\left(14_{R}\right), 10.9\left(14_{S}\right)$ & 3.86 & $2.6\left(14_{R}\right), 11.4\left(14_{s}\right), \sim 0.5(19 ?)$ \\
\hline 18 & 1.87 & $6.9(19), 2.2\left(21_{R}\right)$ & 1.77 & $6.9(19), 2.2\left(21_{R}\right)$ \\
\hline 19 & 5.75 & $6.9(18)$ & 5.65 & $\sim 0.5(15 ?), \sim 1.5\left(21_{\mathrm{S}}\right), 6.9(18)$ \\
\hline $21_{R}$ & 3.79 & $2.2(18), 15.4\left(21_{\mathrm{S}}\right)$ & 3.63 & $2.2(18), 15.5\left(21_{\mathrm{S}}\right)$ \\
\hline $21_{\mathrm{s}}$ & 3.86 & $15.4\left(21_{R}\right)$ & 3.78 & $\sim 1\left(3_{R}\right), 1.5(19), 15.5\left(21_{R}\right)$ \\
\hline $22_{\mathrm{R}}$ & 2.90 & $12.2\left(22_{\mathrm{s}}\right), 6.8\left(3^{\prime}\right)$ & - & - \\
\hline \multirow[t]{2}{*}{$22_{\mathrm{s}}$} & 2.39 & $12.2\left(22_{\mathrm{R}}\right), 11.0\left(3^{\prime}\right)$ & - & - \\
\hline & \multicolumn{2}{|c|}{ Monogagaine } & \multicolumn{2}{|c|}{$3^{\prime}$-Vobasinyl half of vobparicine } \\
\hline $3^{\prime}$ & 4.07 & $6.8\left(22_{\mathrm{R}}\right), 11.0\left(22_{\mathrm{S}}\right), 10.8\left(14_{\mathrm{R}}^{\prime}\right), 1.6\left(14_{\mathrm{S}}^{\prime}\right)$ & 4.53 & $10.1(22), 12.1\left(14_{R}^{\prime}\right), 3.2\left(14_{s}^{\prime}\right)$ \\
\hline $5^{\prime}$ & 3.60 & $5.6\left(6_{\mathrm{R}}^{\prime}\right), 6.2\left(6_{\mathrm{S}}^{\prime}\right), 6.9\left(16^{\prime}\right)$ & 4.00 & $8.2\left(6_{\mathrm{R}}^{\prime}\right), 10.4\left(6_{\mathrm{S}}^{\prime}\right), 3.1\left(16^{\prime}\right)$ \\
\hline $6_{\mathrm{R}}^{\prime}$ & 3.27 & $5.6\left(5^{\prime}\right), 16.7\left(6_{s}^{\prime}\right)$ & 3.21 & $8.2\left(5^{\prime}\right), 14.7\left(6_{\mathrm{s}}^{\prime}\right)$ \\
\hline $6_{S}^{\prime}$ & 3.33 & $6.2\left(5^{\prime}\right), 16.7\left(6_{\mathrm{R}}^{\prime}\right)$ & 3.38 & $10.4\left(5^{\prime}\right), 14.7\left(6_{R}^{\prime}\right)$ \\
\hline $9^{\prime}$ & 7.51 & $8.0\left(10^{\prime}\right)$ & 7.53 & $7.5\left(10^{\prime}\right)$ \\
\hline $10^{\prime}$ & 6.97 & $8.0\left(9^{\prime}\right), 8.0\left(11^{\prime}\right)$ & 7.09 & $7.5\left(9^{\prime}\right), 7.5\left(11^{\prime}\right)$ \\
\hline $11^{\prime}$ & 6.79 & $1.0\left(9^{\prime}\right), 8.0\left(10^{\prime}\right), 8.0\left(12^{\prime}\right)$ & 7.12 & $7.5\left(10^{\prime}\right), 7.5\left(12^{\prime}\right)$ \\
\hline $12^{\prime}$ & 6.55 & $8.0\left(11^{\prime}\right)$ & 7.20 & $7.5\left(11^{\prime}\right)$ \\
\hline $14_{\mathrm{R}}^{\prime}$ & 2.10 & $10.8\left(3^{\prime}\right), 14.8\left(14_{\mathrm{s}}^{\prime}\right), 10.8\left(15^{\prime}\right)$ & 2.64 & $12.1\left(3^{\prime}\right), 15.1\left(14_{s}^{\prime}\right), 12.6\left(15^{\prime}\right)$ \\
\hline $14_{\mathrm{s}}^{\prime}$ & 2.00 & $1.6\left(3^{\prime}\right), 14.8\left(14_{R}^{\prime}\right), 7.8\left(15^{\prime}\right)$ & 1.89 & $3.2\left(3^{\prime}\right), 15.1\left(14_{R}^{\prime}\right), 6.8\left(15^{\prime}\right)$ \\
\hline $15^{\prime}$ & 3.62 & $10.8\left(14_{R}^{\prime}\right), 7.8\left(14_{s}^{\prime}\right), 3.6\left(16^{\prime}\right)$ & 3.74 & $12.6\left(14_{\mathrm{R}}^{\prime}\right), 6.8\left(14_{\mathrm{S}}^{\prime}\right), 3.1\left(16^{\prime}\right)$ \\
\hline $16^{\prime}$ & 3.21 & $6.9\left(5^{\prime}\right), 3.6\left(15^{\prime}\right)$ & 2.74 & $3.1\left(5^{\prime}\right), 3.1\left(15^{\prime}\right)$ \\
\hline $18^{\prime}$ & 1.63 & $6.8\left(19^{\prime}\right)$ & 1.67 & $6.8\left(19^{\prime}\right)$ \\
\hline $19^{\prime}$ & 5.25 & $6.8\left(18^{\prime}\right)$ & 5.41 & $6.8\left(18^{\prime}\right), 1.9\left(21_{\mathrm{R}}^{\prime}\right)$ \\
\hline $21_{\mathrm{R}}^{\prime}$ & 3.42 & $14.9\left(21_{\mathrm{S}}^{\prime}\right)$ & 3.77 & $1.9\left(18^{\prime}\right), 13.8\left(21_{\mathrm{s}}^{\prime}\right)$ \\
\hline $21_{S}^{\prime}$ & 3.01 & $14.9\left(21_{\mathrm{R}}^{\prime}\right)$ & 2.99 & $13.8\left(21_{R}^{\prime}\right)$ \\
\hline $\mathrm{CO}_{2} \mathrm{Me}^{\prime}$ & 3.47 & $\mathrm{~s}$ & 2.47 & $\mathrm{~s}$ \\
\hline $\mathrm{NMe}^{\prime}$ & 2.45 & s & 2.61 & s \\
\hline
\end{tabular}

Note: To distinguish between the two non-equivalent protons of a methylene group the prochirality rules of Hanson [8] were used.

mined. The configuration of $\mathrm{C}^{16}$ was found to be the same as in vobasinol (4) or vobparicine (5) because of the coupling constant of $6.9 \mathrm{~Hz}$ between $\mathrm{H}$ $5^{\prime}$ and $\mathrm{H} 16^{\prime}$. If the configuration at $\mathrm{C} 16^{\prime}$ were the opposite, the coupling constant would be $1-3 \mathrm{~Hz}$. The piperidine ring of the vobasinyl half no longer possesses the usual chair conformation but is now in a boat like conformation. This explains the difference in chemical shifts and coupling constants of the various protons in monogagaine and vobparicine (Table I). Dreiding models also showed that $\mathrm{H}^{\prime}$ ' has the same configurations as in vobparicine (5) and all other alkaloids possessing a vobasinyl half, i.e. the $\beta$ configuration. If the $\mathrm{H}^{\prime}$ ' were to have been in the $\alpha$-position several coupling constants would have been different. The piperidine ring of the apparicine half is thought to have the same conformation as in $\mathrm{O}$ acetyl-vallesamine (6) which also lacks the C16-C22 double bond, because of the similar coupling constants (Table I). As mentioned before the absolute configuration of $\mathrm{H} 15$ and $\mathrm{H} 15^{\prime}$ of monogagaine was deduced by biosynthetical reasoning. This settles 
Table II. ${ }^{13} \mathrm{C}$ NMR data of monogagaine, $\mathrm{O}$-acetyl-vallesamine and 3 '-vobasinyl half of vobparicine $\left(\mathrm{CDCl}_{3}, 75.2,25.15\right.$ and $75.2 \mathrm{MHz}$ respectively).

\begin{tabular}{cccccc}
\hline & \multicolumn{2}{c}{$\delta$} & & & \\
C-nr & Monogagaine & O-Acetyl-vallesamine & C-nr & Monogagaine & $3^{\prime}$-Vobasinyl half of vobparicine \\
\hline 2 & $132.9(?)$ & 128.4 & $2^{\prime}$ & 143.9 & 135.1 \\
3 & 47.0 & 47.4 & $3^{\prime}$ & 40.7 & 33.9 \\
6 & 53.6 & 52.2 & $5^{\prime}$ & 59.7 & 59.7 \\
7 & $110.7(?)$ & 110.0 & $6^{\prime}$ & 22.0 & 19.4 \\
8 & 128.0 & 127.8 & $7^{\prime}$ & $110.7(?)$ & 109.5 \\
9 & 118.4 & 118.5 & $8^{\prime}$ & $128.1(?)$ & 129.9 \\
10 & 119.3 & 119.4 & $9^{\prime}$ & 117.2 & 117.7 \\
11 & 122.8 & 122.9 & $10^{\prime}$ & 118.1 & 119.8 \\
12 & 110.7 & 110.5 & $11^{\prime}$ & 121.2 & 122.2 \\
13 & 135.7 & 135.3 & $12^{\prime}$ & 110.7 & 110.0 \\
14 & 26.8 & 25.2 & $13^{\prime}$ & 137.0 & 135.8 \\
15 & 33.7 & 34.7 & $14^{\prime}$ & 26.8 & 33.7 \\
16 & 51.5 & 55.8 & $15^{\prime}$ & 33.6 & 33.4 \\
18 & 13.7 & 14.0 & $16^{\prime}$ & 46.6 & 46.0 \\
19 & 123.8 & 125.4 & $18^{\prime}$ & 12.6 & 12.3 \\
20 & $132.4(?)$ & 132.8 & $19^{\prime}$ & 118.7 & 119.6 \\
21 & 55.1 & 54.6 & $20^{\prime}$ & 138.8 & 136.9 \\
22 & 36.5 & - & $21^{\prime}$ & 56.0 & 52.2 \\
& & & $\mathrm{NMe}^{\prime}$ & 43.0 & 42.3 \\
& & $\mathrm{CO}_{2} \mathrm{Me}^{\prime}$ & 52.9 & 50.1 \\
& & $\mathrm{CO}_{2} \mathrm{Me}^{\prime}$ & 173.5 & not observed \\
\hline
\end{tabular}

Note: The assignment of monogagaine signals, which differ less than 3 ppm from each other, may be interchanged. (?): very weak signal.

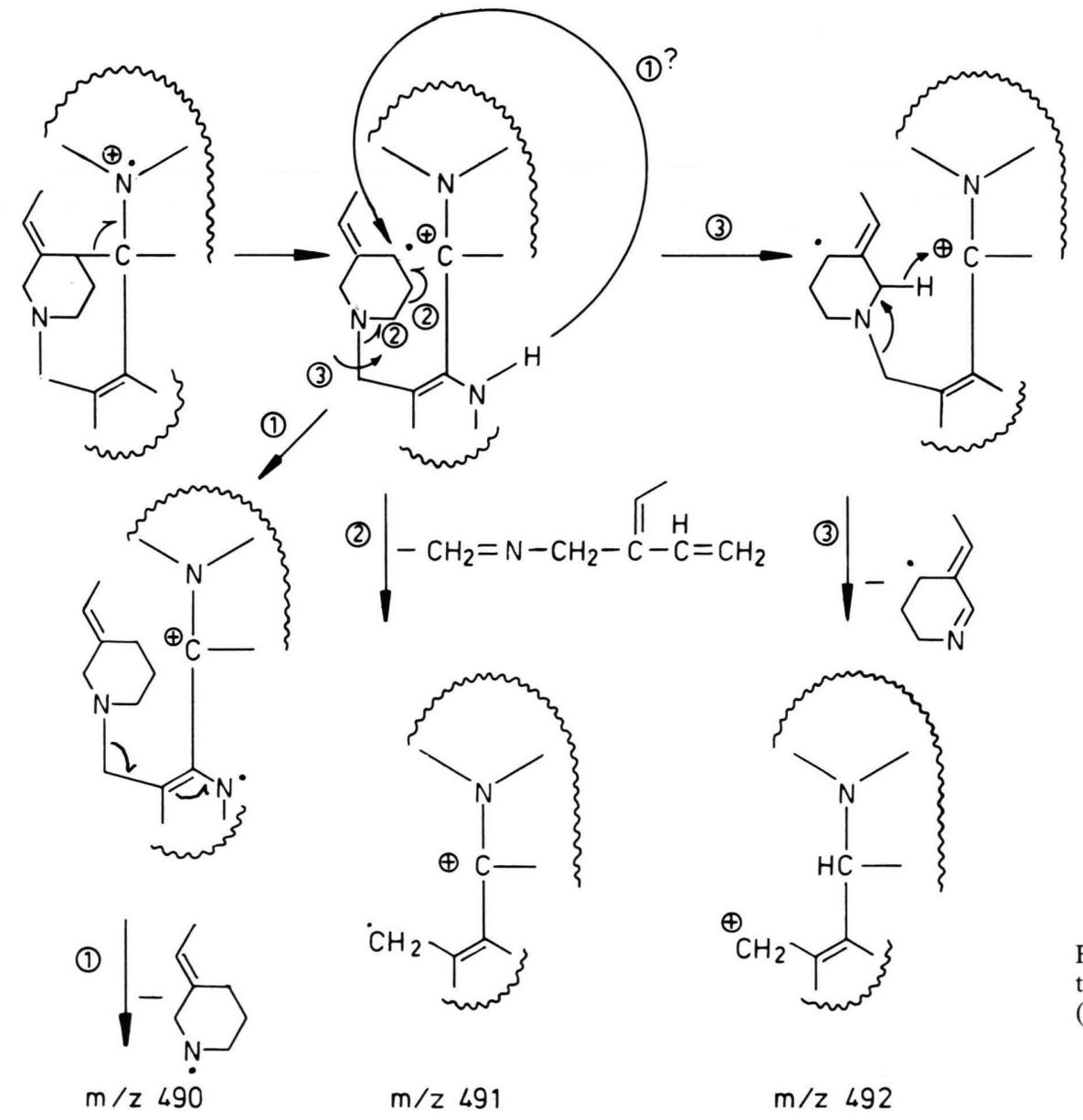

Fig. 3. Possible MS fragmentation pattern of monogagaine (1).

$\mathrm{m} / \mathrm{z} \quad 492$ 
automatically the stereochemistry of all adjacent carbon atoms. A CD spectrum was recorded to allow a comparison in case monogagaine is isolated from another species. The CD spectrum was similar to the $\mathrm{CD}$ spectra of the voacamine type of alkaloids but this could have been a coincidence.

The only carbon atom the relative stereochemistry of which could not be determined from the ${ }^{1} \mathrm{H}$ NMR data is the spiro atom C16. Dreiding models showed that both configurations at $\mathrm{C} 16$ are possible. A distinction between the possible $\mathrm{C} 16$ configurations could be made by means of NOE difference spectroscopy by which it is possible to make long range through space connections between various protons. In case of a $16 \mathrm{~S}$ configuration NOE's were expected between $\mathrm{H} 12^{\prime}$ and $\mathrm{H} 6_{\mathrm{R}} / \mathrm{H} 6_{S} / \mathrm{H} 14_{\mathrm{R}}$ if the 8 -membered ring of the apparicine derived half has the same conformation as in O-acetyl-vallesamine (6). The alternative conformation of the 8-membered ring in which $\mathrm{H} 6_{\mathrm{s}}$ lies in the plane of the indole nucleus was considered less likely because the Dreiding models showed that in that case $\mathrm{H} 14_{\mathrm{R}}(\delta 2.85 \mathrm{ppm})$ would be below the indole nucleus and would have been strongly shielded. As it happens just the reverse is true, this proton is somewhat deshielded in comparison with O-acetyl-vallesamine (6) (Table I). In case of a $16 \mathrm{R}$ configuration NOE's were expected between $\mathrm{H} 12^{\prime}$ and $\mathrm{H} 18$ and possibly also $\mathrm{H} 1 / \mathrm{H} 15$. Irradiation of $\mathrm{H} 6_{\mathrm{R}}$ gave, apart from a strong NOE for $\mathrm{H} 6_{\mathrm{s}}$, only a weak NOE for $\mathrm{H} 9$. Irradiation of $\mathrm{H} 6_{\mathrm{s}}$ gave a strong NOE for $\mathrm{H} 6_{\mathrm{R}}$ and further only a weak NOE for H9. These NOE's confirmed unambigiously the ${ }^{1} \mathrm{H}$ NMR assignment of the two aromatic parts. Irradiation of $\mathrm{H} 12^{\prime}$ gave an NOE for $\mathrm{H} 11^{\prime}$ and an NOE for $\mathrm{H} 14_{\mathrm{R}}$. Irradiation of $\mathrm{H} 14_{\mathrm{R}}$ and, as it was also necessary, $\mathrm{H} 22_{\mathrm{R}}$ gave strong NOE's for H12', $\mathrm{H} 3^{\prime}, \mathrm{H} 22_{\mathrm{s}}$ and $\mathrm{H} 14_{\mathrm{s}}$. Irradiation of $\mathrm{H} 18$ gave no significant NOE's with exception of its direct neighbour H19. Finally irradiation of $\mathrm{H} 1$ gave no significant NOE's at all. All the observed NOE's were positive. The results of the NOE experiments are summarized in Table III.

From the above data, especially the strong NOE between $\mathrm{H} 12^{\prime}$ and $\mathrm{H} 14_{\mathrm{R}}$ it follows that $\mathrm{C} 16$ has the $\mathrm{S}$ configuration. However, from the absence of an NOE between $\mathrm{H} 6_{\mathrm{R}} / \mathrm{H} 6_{S}$ and $\mathrm{H} 12^{\prime}$ it must be concluded that the 8-membered ring of the apparicine derived half does not have the conformation predicted by the Dreiding model but a version of this conformation strained in such way that $\mathrm{H} 6_{R}$ lies on
Table III. NOE connectivities.

\begin{tabular}{ll}
\hline Proton irradiated & NOE observed for \\
$\mathrm{H} 1$ & - \\
$\mathrm{H} 6$ & $\mathrm{H} 6_{\mathrm{S}}(++), \mathrm{H} 9(+)$ \\
$\mathrm{H} 66_{\mathrm{S}}$ & $\mathrm{H} 6_{\mathrm{R}}(++), \mathrm{H} 9(+)$ \\
$\mathrm{H} 14_{\mathrm{R}}$ and $\mathrm{H} 22_{\mathrm{R}}$ & $\mathrm{H} 14_{\mathrm{S}}(++), \mathrm{H} 22_{\mathrm{S}}(++), \mathrm{H} 3^{\prime}(++)$ \\
$\mathrm{H} 18$ & $\mathrm{H} 12^{\prime}(++)$ \\
$\mathrm{H} 12^{\prime}$ & $\mathrm{H} 14_{\mathrm{R}}(++)$ \\
\hline
\end{tabular}

Note: $(++)$ : strong NOE; $(+)$ : weak NOE.

one side of the indole plain and $\mathrm{H} 6_{\mathrm{S}}$ on the other side instead of being on the same side. This would also fit the smaller chemical shift difference between $H 6_{R}$ and $\mathrm{H} 6_{\mathrm{S}}$ in monogagaine as compared to O-acetylvallesamine $(0.35 \mathrm{ppm}$ and $0.65 \mathrm{ppm}$ respectively). Supporting evidence for the $16 \mathrm{~S}$ configuration was obtained from the chemical shift of $\mathrm{H} 14_{\mathrm{R}}(2.85 \mathrm{ppm})$ and $\mathrm{H} 14_{\mathrm{s}}(1.83 \mathrm{ppm})$. In $\mathrm{O}$-acetyl-vallesamine the same protons have shifts of 2.33 and $2.03 \mathrm{ppm}$ respectively. These deshielding and shielding effects can be explained by the position of these protons near the indole nucleus of the vobasinyl half. $\mathrm{H} 14_{\mathrm{R}}$ (2.85 ppm) which is close to $\mathrm{H} 12^{\prime}$ according to the NOE experiments lies in the plain of the indole nucleus and is therefore $0.5 \mathrm{ppm}$ deshielded. $\mathrm{H} 14_{\mathrm{s}}$ (1.85 ppm) lies somewhat above the indole nucleus and is thus $0.2 \mathrm{ppm}$ shielded. If $\mathrm{C} 16$ possessed the $\mathrm{R}$ configuration the $\mathrm{H} 14$ protons would be far away from the indole nucleus and would probably possess shifts not greatly different from those found for $\mathrm{O}$-acetyl-vallesamine. Thus monogagaine is thought to have the configuration depicted in $\mathbf{1}$.

Biogenesis. It is speculated that monogagaine is formed in a similar fashion as vobparicine and the dimeric alkaloids of the voacamine type i.e. by an attack of the electrophilic $\mathrm{C} 3$ of vobasinol (4) on an electron rich centre such as in apparicine (2) C22. However, in contrast with vobparicine (5) the reaction does not stop at this stage and is immediately followed by ring closure between the nitrogen of the 3 '-vobasinyl half and C16 of the apparicine half (Fig. 4). It is not considered likely that vobparicine (5) is a precursor or an intermediate in the biogenesis of monogagaine (1). More likely they are merely the different results of a reaction between apparicine and vobasinol which can proceed in two distinctly different ways depending on the conditions.

No attempt to synthesize monogagaine (1) was made because under the conditions usually favour- 


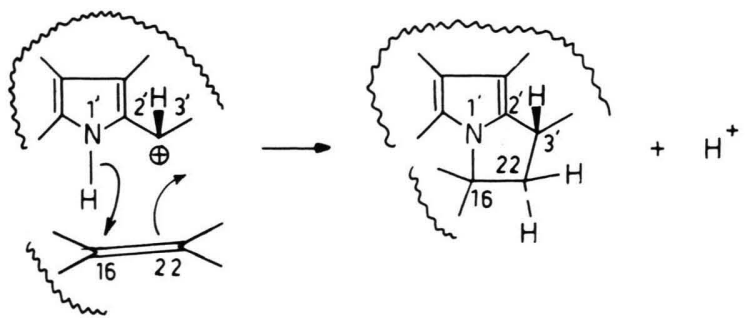

Fig. 4. Possible biogenetical pathway leading to monogagaine (1).

able for the formation of this type of alkaloid the mixture of vobasinol (4) and apparicine (2) gave only vobparicine (5) in detectable amounts [6]. For the same reason it is not considered likely that monogagaine (1) is an artefact. In a preliminary screening (biogram method) monogagaine showed antimicrobial activity against Bacillus subtilis.

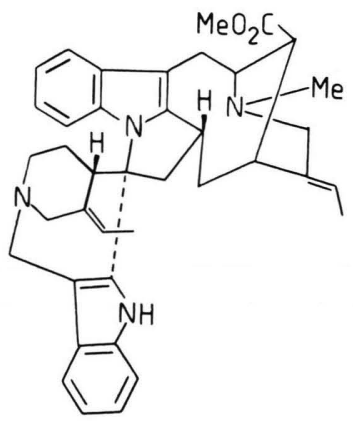

1: Monogagaine.

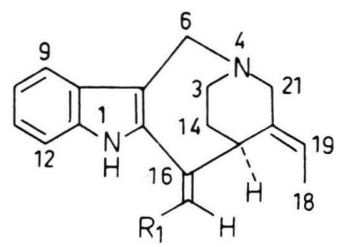

2: Apparicine $\mathrm{R}_{1}=\mathrm{H}$.

5: Vobparicine $R_{1}=3^{\prime}$-vobasinyl.

3: 3'-Vobasinyl.

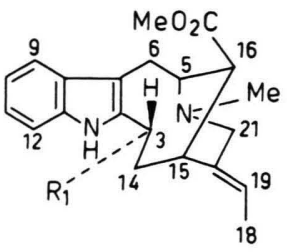

4: Vobasinol $\mathrm{R}_{1}=\mathrm{OH}$.

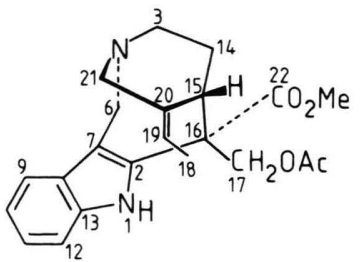

6: O-Acetyl-vallesamine.

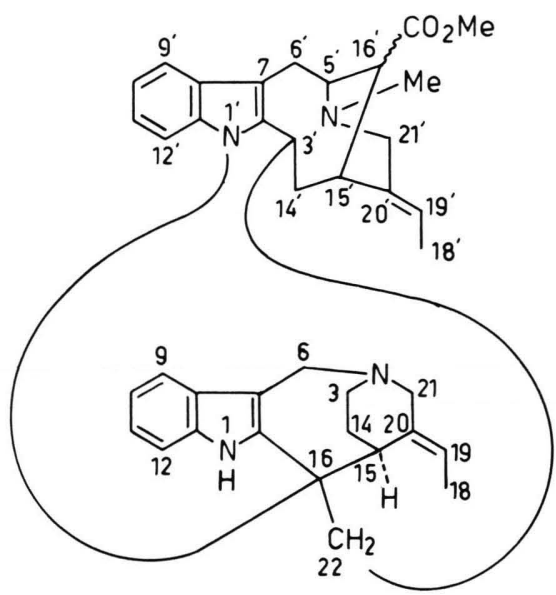

7: Monogagaine.

\section{Experimental}

The botanical details and procedures used for the isolation of monogagaine can be found in the previous publications [2,3]. UV and CD spectra were recorded in $\mathrm{MeOH}$. 300 and $500 \mathrm{MHz}{ }^{1} \mathrm{H}$ NMR spectra were recorded in $\mathrm{CDCl}_{3}$ on a Bruker WM 300 and WM 500. respectively. All NOE experiments were carried out at $300 \mathrm{MHz}$. The COSY spectrum was recorded by employing the pulse sequence proposed by Bax et al. [9], i.e. the second $90^{\circ}$ pulse was replaced by a $45^{\circ}$ pulse in order to obtain a better resolution near the diagonal. The $75.2 \mathrm{MHz}$ ${ }^{13} \mathrm{C}$ NMR spectrum was recorded in ${ }^{12} \mathrm{C}$ enriched $\mathrm{CDCl}_{3}$ without TMS $\left(\mathrm{CDCl}_{3}=77.0 \mathrm{ppm}\right)$ on a Bruker WM 300. The FD-MS was recorded on a VG- 
Analytical ZAB-HF mass spectrometer with a combined EI/FI/FD source. The high resolution EI-MS was recorded on a Kratos MS 50.

TLC: For the determination of the $R_{f}$ value the following systems were used:

S1: toluene $-100 \%$ EtOH satd. with $\mathrm{NH}_{3} \quad(19: 1)^{*}$

S2: (iso- $\mathrm{Pr})_{2} \mathrm{O}-100 \%$ EtOH satd. with $\mathrm{NH}_{3}(9: 1)^{*}$

S3: $\mathrm{CHCl}_{3}-\mathrm{MeOH}$

Spectral data monogagaine (1): $R_{f}$ value in $\mathrm{S} 1$ 0.48, S2 0.31, S3 0.39; Colour with $\mathrm{FeCl}_{3} / \mathrm{HClO}_{4}$ : gold, changing upon heating via dark blue to greyblack; UV $\lambda_{\max }$ : 222, 282 (sh), 288, 297 (sh) nm; CD $\lambda(\Delta \varepsilon): 208(0.0), 218(-45), 226(0.0), 233(+73)$, $263(+14), 287(+15), 350(0.0)$; FD-MS (18 mA) $\mathrm{m} / z$ (rel. int.) $600(100 \%)$; EI-MS $\left(220^{\circ} \mathrm{C}\right) \mathrm{m} / z$ (rel. int.) 614 (2), $600\left(\mathrm{M}^{+}, 38\right), 599(6), 598(6), 569$ (3),

* Prior to development the plates were left in an atmosphere of $\mathrm{NH}_{3}$ for $20 \mathrm{~min}$. After development the plates were sprayed with $0.2 \mathrm{M} \mathrm{FeCl}_{3}$ in $35 \% \mathrm{HClO}_{4}$, followed by heating with hot air.
568 (4), 493 (10), 492 (32), 491 (35), 490 (74), 489 (14), 460 (7), 459 (9), 458 (18), 405 (8), 309 (13), 295 (18), 277 (11), 206 (13), 183 (10), 182 (72), 181 (26), 180 (100), 149 (19), 133 (42), 129 (13), 124 (12), 123 (11), 122 (46), 120 (10), 111 (14), 110 (15), 109 (12), 105 (11); High resolution MS: 600.3452 (calcd for $\mathrm{C}_{39} \mathrm{H}_{44} \mathrm{~N}_{4} \mathrm{O}_{2}$ 600.3464); ${ }^{1} \mathrm{H}$ NMR, see Fig. 1 and Table I; ${ }^{13} \mathrm{C}$ NMR, see Table II.

We wish to thank Dr. A. J. M. Leeuwenberg for the collection and identification of the plant material, Dr. B. C. Das (Gif sur Yvette) for recording the high-resolution MS, Prof. N. M. N. Nibbering (University of Amsterdam) for the useful discussion of the mass spectral data, and the Netherlands Foundation for Chemical Research (S. O. N.) for financial aid in purchasing the CD-apparatus and the VGAnalytical ZAB-HF mass spectrometer. Financial support by the "Fonds Harald Quintus Bosz" and the "Van Leersum Fonds" for collecting the plant material is gratefully acknowledged.
[1] Part 14 in the series "Pharmacognostical studies of Tabernaemontana species". For part 13 see: T. A. van Beek and R. Verpoorte, Fitoterapia, accepted for publication.

[2] T. A. van Beek, R. Verpoorte, and A. Baerheim Svendsen, J. Nat. Prod., in press.

[3] P. Perera, F. Sandberg, T. A. van Beek, and R. Verpoorte, Phytochemistry, submitted for publication.

[4] T. A. van Beek, R. Verpoorte, and A. Baerheim Svendsen, J. Chromatogr. 298, 289 (1984).
[5] T. A. van Beek, R. Verpoorte, A. Baerheim Svendsen, A. J. M. Leeuwenberg, and N. G. Bisset, J. Ethnopharmacol. 10, 1 (1984).

[6] T. A. van Beek, R. Verpoorte, and A. Baerheim Svendsen, Tetrahedron Lett. 25, 2057 (1984).

[7] X. Z. Feng, C. Kan, H.-P. Husson, P. Potier, S.-K. Kan, and M. Lounasmaa, J. Nat. Prod. 47, 117 (1984).

[8] K. R. Hanson, J. Am. Chem. Soc. 88, 2731 (1966).

[9] A. Bax and R. Freeman, J. Magn. Reson. 44, 542 (1981). 